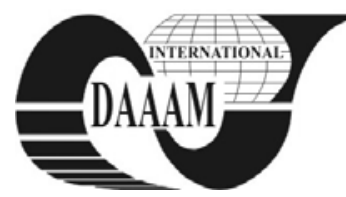

Annals of DAAAM for 2011 \& Proceedings of the 22nd International DAAAM Symposium, Volume 22, No. 1, ISSN 1726-9679 ISBN 978-3-901509-83-4, Editor B. Katalinic, Published by DAAAM International, Vienna, Austria, EU, 2011 Make Harmony between Technology and Nature, and Your Mind will Fly Free as a Bird Annals \& Proceedings of DAAAM International 2011

\title{
STRUCTURAL-KINEMATIC COMPONENTS OF A STEERING SYSTEM FOR VEHICLES WITH INTEGRAL STEERING
}

\author{
MACAVEIU, M[ircea] D[ragos] \& ALEXANDRU, P[etre]
}

\begin{abstract}
The paper presents a mechanical system for turning the rear wheels of a vehicle with four-wheel drive, under integral steering conditions. The rear steering box - from the author's perspective - includes (contains) a cam with double profiles that drives the slide block, or the rocking lever of the steering mechanism. The drive of the cam is performed by the steering rack of the front axle. The kinematic correlations of the steering system components of a vehicle with integral steering are given as a purely mechanical structure, driven by the steering wheel.
\end{abstract}

Key words: CAM, mechanism, steering box, integral steering

\section{INTRODUCTION}

For vehicles with four-wheel drive, traditionally, the rear wheels are turned in the opposite direction to the front ones, in order to increase the maneuverability, i.e. to reduce the steering radius. By turning the wheels in such a way, the vehicle stability - at high speeds - will be compromised.

To ensure both a good maneuverability and stability, solutions are explored for the so-called "integral steering", where, at the beginning of a turn -when vehicle travelling at high speeds the rear wheels will be turned in the same direction to the front ones (ensuring a good stability), and as the curvature of the trajectory increases, the rear wheels to return in normal position (for going straight) and then will be turned in the opposite direction to the front ones (obtaining small turning radius). A number of researches have proposed various mechanisms for the steering box of the rear axle to fulfill the requirements of the integral steering, highlighting papers (Fraukawa, 1985) for steering box with 4R linkage,-- driven by two cranks; as well as paper (Kido, 1990) - for steering box with cam mechanisms (cam with a pair of cam followers which are hold by a follower support).

The authors' papers (Alexandru et al., 2011, Macaveiu \& Alexandru, 2011)- with the idea of a pure mechanical structure - develop and underlie variants of linkages and cam mechanisms for the steering box of the rear axle which will drive the rear wheels and turn them under the integral steering requirements, respectively: at the beginning of a turn (at high speeds) the rear wheels are turned in the same direction to the front ones, return in normal position and then turn in the opposite position.

\section{STRUCTURAL-KINEMATIC COMPONENTS}

The paper presents the correlation among characteristics of steering transmission components of vehicles with two steering axles for a purely mechanical structure under the integral steering condition.

The purely mechanical structure will be driven only by the car's steering wheel. Therefore, the transmission from the steering wheel to the wheels is following the kinematic chain (fig.1.a): the front steering box (e.g. rack and pinion), the front steering mechanism (e.g. with central rack) and (in parallel) a device for driving the longitudinal shaft (e.g. rack and pinion gear); reducer (e.g. spur-gear), the rear steering box (e.g. cam mechanism), the rear steering mechanism (e.g. translational slide block).

The kinematical parameters from figure 1 are:

$V_{a}$ - vehicle speed (direction of travel),

$\theta_{e, i}$-turning angle of the front wheels ( $e, i$ - exterior/interior to the vehicle path),

$\varphi_{v}$ - steering wheel rotation angle,

$S_{c}$ - the displacement of the front steering rack,

$\varphi_{t}$ - the rotation angle of the rear translation shaft,

$\varphi_{c}$ - the rotation angle of the cam of the rear steering box,

$S_{t}$ - the displacement of the translational slide block of the rear steering mechanism,

$\sigma_{e, i}$-turning angle of the rear wheels $(e, i-$ exterior/interior to the vehicle path),

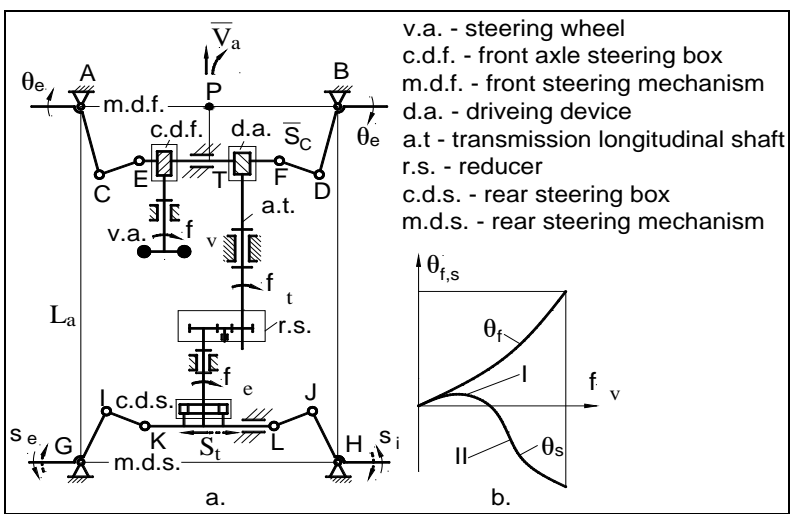

Fig. 1. Transmission components of the steering system

By turning the steering wheel with the angle $\varphi_{v}$, the displacement $S_{c}$ of the rack is obtained:

$$
S_{c}=r_{p} \varphi_{v}=\frac{m_{t} z_{p}}{2} \varphi_{v}=\frac{m_{n}}{2 \cos \beta} z_{p} \varphi_{v},
$$

where: $r_{p}$ - the pinion radius; $m_{t}-$ teeth module; $z_{p}$ - number of teeth of the pinion; $m_{n}$ - nominal module, $\beta$ - helix angle.

The rack displacement $S_{c}$ causes the turning of the front wheels with the angle $\theta_{e} / \theta_{i}$, the function $\theta_{e}\left(S_{c} / \varphi_{v}\right) / \theta_{i}\left(S_{c} / \varphi_{v}\right)$ being determined by the geometry ACEFDB of the steering mechanism. The correlation $\theta_{i}\left(\theta_{e}\right)$ shows the turning law of the front wheels.

The steering angle $\theta_{f}$ of the front axle, is considered to be

$$
\theta_{f}=\left(\theta_{e}+\theta_{i}\right) / 2 \text {, }
$$

thus, is dependent on the geometry of the steering system, i.e. the length of the bars,

$a=\overline{A C}=\overline{B D}, b=\overline{A B}, l=\overline{C E}=\overline{D F}, c=\overline{E F}, e=\overline{P T}$, as well as on the gear characteristics of the steering box $m_{n}, \beta, z_{p}$, based on $\theta_{f}\left(\varphi_{v}\right)$ (fig.1.b).

For the device that drives the longitudinal shaft, the rotation of the transmission shaft is obtained from the rack, 


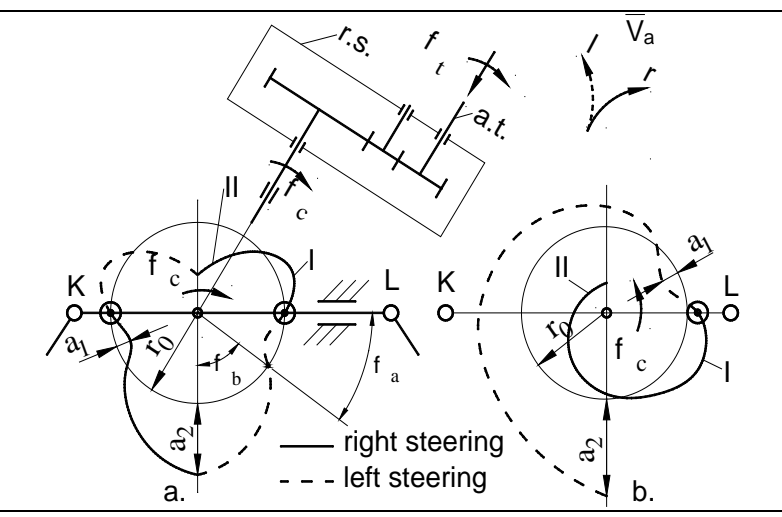

Fig. 2. Cams arrangement in the steering box of the rear axle

through a gear of the same module $m_{n}$ and number of teeth $z_{r}$.

$$
\varphi_{t}=\frac{S_{C}}{r_{r}}=\frac{r_{p} \varphi_{v}}{r_{r}}=\frac{z_{p}}{z_{r}} \varphi_{v} .
$$

The transmission reducer, positioned before the steering box of the rear axle, serves to transmit to the central element of the steering box a rotational movement $\varphi_{c}$, through which the two axles are correlated. Thus, for its transmission ratio $i_{t}$, the rotation angle of the central element of the steering box is:

$$
\varphi_{c}=\frac{\varphi_{t}}{i_{t}}=\frac{z_{p}}{z_{r} i_{t}} \varphi_{v} .
$$

ratio $i_{t}$ can be positive or negative.

The steering box of the rear axle, depending on its geometry, will cause the displacement $S_{t}$ of the central cam follower/slide block according to the cam profile - fig. 2.a, for example, within a sine law of amplitude $a_{1}$, respectively $a_{2}$,

$$
S_{t}=a_{1} \sin \frac{\pi}{\varphi_{a}} \varphi_{c}, \text { respectiv } S_{t}=a_{2} \sin \frac{\pi}{2 \varphi_{b}} \varphi_{c} .
$$

where, $\varphi_{a}$ and $\varphi_{b}$ are the maximum rotation angles of the cam, for going through the profile of the cam.

For steering to the right, if the ratio $i_{t}$ is positive, the rotation $\varphi_{c}$ has the same direction as $\varphi_{v}$, and the cam profile will be as in figure 2.a (the profile with continuous line). For the negative ratio $i_{t}$, the direction of the rotation $\varphi_{c}$ is opposed to $\varphi_{v}$ (fig.2.b), the cam profile being symmetrical (inverted) to the previous case. In both cases from figure 2, the cam follower was considered with a follower support that holds a pair of rollers. The profile with dotted line refers to steering to the left. With the value of the ratio $i_{t}$, the maximum rotation angle of the cam is determined: for the one with follower support with tow roller being $90^{\circ}$, with the angle $\varphi_{a}$ (for the profile I) and $\varphi_{b}=\pi / 2-\varphi_{a}$ (for the profile II).

For the follower with one roller, the rotation angle of the cam can reach up to $270^{\circ}$, in one way or the other (fig.2.c), in this case $\varphi_{b}=3 \pi / 2-\varphi_{a}$. Thus, we obtain the dependency

$$
S_{t}=a_{1} \sin \frac{\pi}{\varphi_{a}}\left(\frac{z_{p}}{z_{r} i_{t}} \varphi_{v}\right) \text {, resp. } S_{t}=a_{2} \sin \frac{\pi}{2 \varphi_{b}}\left(\frac{z_{p}}{z_{r} i_{t}} \varphi_{v}\right) \text {. }
$$

According to the displacement $S_{t}$ of the central slide block and to the steering mechanism geometry GHIJKL of the rear axle, which usually corresponds with the one of the front axle mechanism, rear wheels turnings $\sigma_{e}\left(\varphi_{v}\right)$ and $\sigma_{i}\left(\varphi_{v}\right)$ are obtained. The turning angle $\theta_{s}$ of the rear axle

$$
\theta_{S}=\left(\sigma_{e}+\sigma_{i}\right) / 2
$$

is depending on the rotation $\varphi_{v}$ of the steering wheel $-\theta_{s}\left(\varphi_{v}\right)$. Both angles of turning, $\theta_{f}\left(\varphi_{v}\right)$ and $\theta_{s}\left(\varphi_{v}\right)$ define the turning type/stage of the vehicle with two steering axles.

If the steering box of the rear axle is built from a linkage mechanism, e.g. the mechanism with the rocker, it needs, as seen above, two driving elements.

\section{NUMERICAL APPLICATION}

For reals values of a vehicle:

$r_{0}=60 \mathrm{~mm} ; a=116.8 \mathrm{~mm} ; b=1299 \mathrm{~mm} ; c=639 \mathrm{~mm} ; l=326.2$ $m \mathrm{~mm} e=131.3 \mathrm{~mm} ; m_{n}=2 ; z_{p}=7 ; \beta=10^{\circ} \rightarrow r_{p}=7.11 \mathrm{~mm} ; L_{a}=2475$ $\mathrm{mm}$.

results the values from table 1

\begin{tabular}{|c|l|l|l|l|l|l|l|}
\hline $\mathrm{S}_{\mathrm{C}}[\mathrm{mm}]$ & $\theta_{\mathrm{f}}\left[^{0}\right]$ & $\varphi_{\mathrm{v}}\left[^{0}\right]$ & $\varphi_{\mathrm{t}}\left[^{0}\right]$ & \multicolumn{3}{|c|}{$\varphi_{\mathrm{c}}\left[^{0}\right]$} & $\mathrm{S}_{\mathrm{t}, \mathrm{II}}$ \\
\hline 0 & 0 & 0 & 0 & $\mathrm{i}_{\mathrm{t}}=3$ & $\mathrm{i}_{\mathrm{t}}=1.5$ & $\mathrm{i}_{\mathrm{t}}=1$ & $\begin{array}{l}0 \\
\mathrm{~mm}\end{array}$ \\
\hline 10 & $5^{\circ} 01^{\prime}$ & 80.5 & 40.2 & 13.4 & 26.8 & 40.2 & 10 \\
\hline 20 & $10^{\circ} 05^{\prime}$ & 161 & 80.5 & 26.8 & 53.6 & 80.5 & 0 \\
\hline 30 & $15^{\circ} 14^{\prime}$ & 241.5 & 120.7 & 40.2 & 80.5 & 120.7 & 14.71 \\
\hline 40 & $20^{\circ} 33^{\prime}$ & 322 & 161 & 53.7 & 107.3 & 161 & 27.90 \\
\hline 50 & $26^{\circ} 06^{\prime}$ & 402.5 & 201.2 & 67.1 & 134.2 & 201.2 & 37.89 \\
\hline 60 & $32^{\circ} 02^{\prime}$ & 483 & 241.5 & 80.5 & 161 & 241.5 & 43.74 \\
\hline 67 & $36^{\circ} 33^{\prime}$ & 540 & 270 & 90 & 180 & 270 & 45 \\
\hline
\end{tabular}

Tab. 1 Numerical results for the steering system

$S_{t}$ representing the displacement of the slide block of the rear steering mechanism.

$$
\begin{aligned}
& S_{t_{I}}=a_{1} \sin \frac{\pi}{\varphi_{a}} \varphi_{c}=10 \sin \frac{180}{26.8} \varphi_{c}, \\
& S_{t_{I I}}=a_{2} \sin \frac{\pi}{2 \varphi_{b}} \varphi_{c}=45 \sin \frac{90}{63.2} \varphi_{c} .
\end{aligned}
$$

Respectively the polar radius of the came according to table 2 :

$$
r_{I}=r_{0} \pm S_{t_{I}}, r_{I I}=r_{0} \mp S_{t_{I I}} .
$$

\begin{tabular}{|c|l|c|c|c|c||c|c|c|c|c|}
\hline $\begin{array}{c}\mathrm{r}_{\mathrm{I}, \mathrm{II}} \\
{[\mathrm{mm}} \\
]\end{array}$ & 60 & 67 & 70 & 67 & 60 & 45.3 & 32.1 & 22.1 & 16.2 & 15 \\
\cline { 2 - 9 } & 52.9 & 50 & 52.9 & 60 & 74.7 & 87.9 & 97.8 & 103.7 & 105 \\
\hline
\end{tabular}

Tab. 2. Values of the cams polar radius

And the obtained function from figure 3

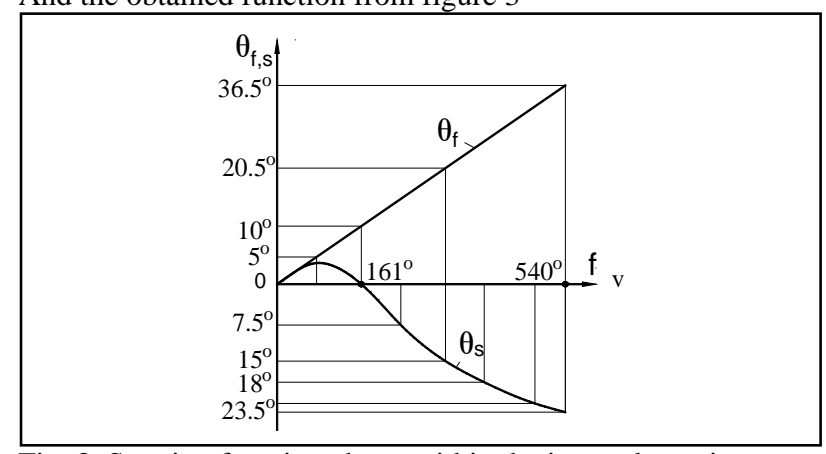

Fig. 3. Steering function charts within the integral steering

Conclusion: the steering system with the cam mechanism meet the requirements of the integral steering (fig. 3 related to fig.1,b)

\section{ACKNOWLEDGEMENTS}

Supported by CNCS, project number PNII-IDEI 607/2008

\section{REFERENCES}

Alexandru, P., Macaveiu, D. \& Alexandru, C. (2011). Structure of linkages and cam gear for integral steering of vehicles, ICAMAME - WASET, Vol. 7, No. 80, (August 2011), pg. 675-681, ISSN 2010-3778

Fraukawa, Y. Steering device for vehicle, U.S. Patent no. 4538824

Kido, T. Steering mechanism for vehicle rear wheels. U.S. Patent no. 4943074

Macaveiu, D., Alexandru, P.(2011) Gear Mechanism for integral steering of vehicles, 15th International Conference 